\title{
A ciência como sublimação: o desafio da objetividade na sociologia reflexiva de Pierre Bourdieu
}

GABRIEL PETERS"

\section{Resumo}

O artigo investiga a resposta de Bourdieu a um problema clássico na epistemologia das ciências sociais: como é possível um conhecimento objetivo do mundo societário se os pontos de vista dos cientistas sociais são condicionados por seu pertencimento a esse mundo? O texto expõe sua tese de que a sociologia da sociologia, ao revelar os condicionantes sociais do pensamento sobre o social, possibilita uma margem de liberdade em relação a tais condicionantes. Longe de desembocar no relativismo pluriperspectivista, portanto, a sociologia reflexiva de Bourdieu é voltada à conquista da objetividade. O trabalho também mostra que sua noção de reflexividade se articula a uma concepção de objetividade científica como efeito "sublimado" da competição regrada entre agentes interessados que caracteriza o campo da ciência. Por fim, embora simpático à proposta de Bourdieu, o artigo é pontuado com considerações críticas sobre as tensões a ela inerentes: a) o reconhecimento do caráter "posicionado" das suas intervenções sociológicas versus a intenção de capturar o espaço inteiro dos pontos de vista sociocientíficos; b) a defesa de uma reflexividade sociológica calcada na dialética racional do campo científico versus a admissão de que as ciências sociais não possuem suficiente autonomia para levar essa dialética racional a cabo.

Palavras-chave: Pierre Bourdieu. Objetividade. Reflexividade. Epistemologia das Ciências Sociais. Sociologia do Conhecimento.

* Universidade Federal da Bahia, Brasil 


\section{Science as sublimation: the challenge of objectivity in Pierre Bourdieu's reflexive sociology}

\section{Abstract}

The article investigates Bourdieu's answer to a classic problem in the epistemology of the social sciences: how is an objective knowledge of the social world possible if social scientists' points of view are conditioned by their belonging to this world? The text presents his thesis that the sociology of sociology, by revealing the social conditionings of social thought, enables a margin of freedom from these conditionings. Far from sliding into multiperspectivistic relativism, therefore, Bourdieu's reflexive sociology is geared towards the conquest of objectivity. The paper also shows that his notion of sociological reflexivity is articulated to a conception of scientific objectivity as a "sublimated" effect of the rule-bound competition between interested agents that characterizes the field of science. Finally, although sympathetic to Bourdieu's proposal, the article is interspersed with critical considerations about the tensions that inhere to it: a) the recognition of the "positioned" nature of his sociological interventions versus the intention of capturing the whole space of social-scientific viewpoints; b) the defense of a sociological reflexivity based on the rational dialectic of the scientific field versus the admission that social sciences do not possess enough autonomy to bring this rational dialectic about.

Keywords: Pierre Bourdieu. Objectivity. Reflexivity. Epistemology of the social sciences. Sociology of knowledge. 


\section{Introdução: a façanha de Münchhausen}

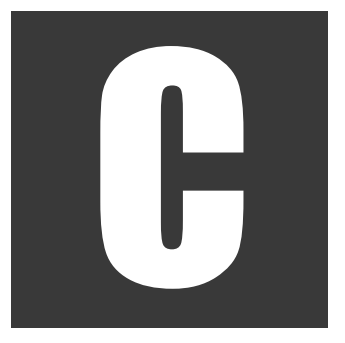

onta o personagem mitômano Barão de Münchhausen que, certa vez, ele andava em seu cavalo quando, de repente, ambos começaram a afundar em solo pantanoso. Não tendo onde agarrar-se, o Barão estava prestes a se despedir desse mundo até que teve a brilhante ideia de se retirar do pântano, juntamente com seu cavalo, puxando-se pelos próprios cabelos. Em discussões de inspiração lukácsiana sobre a objetividade nas ciências sociais, Löwy $(1991$; 2000) recorreu engenhosamente a esta anedota para atacar a ideia de que o conhecimento objetivo sobre o mundo social poderia ser adquirido através de um mero esforço de controle consciente dos próprios preconceitos e "pré-noções" (Durkheim). A analogia proposta por Löwy sugere que tal injunção metodológica, segundo a qual o autocontrole psicológico seria suficiente para neutralizar os próprios vieses (cognitivos, valorativos, afetivos etc.) na caracterização científica do mundo societário, soa tão irrealista quando a façanha narrada pelo simpático mentiroso Münchhausen.

O valor evocativo da anedota löwyiana merece respeito, tanto mais porque se soma à sua erudita reconstrução das respostas positivistas, historicistas e marxistas ao desafio da objetividade nas ciências sociais, em face dos condicionamentos sociopolíticos que pesam sobre as "visões de mundo" dos seus praticantes (Löwy, 2000, p. 12). Seu tour de force intelectual encontra uma espécie de anticlímax, no entanto, ao desembocar, na conclusão do livro, em uma versão parcamente modificada da tese lukácsiana quanto à superioridade epistemológica do ponto de vista do proletariado. Tal tese, que já era um bocado problemática quando da publicação de História e Consciência de Classe por Lukács em 1923 (cf. Jay, 1984, p. 112-27; Kolakowski, 1978, p. 299-300; Vandenberghe, 2009, p. 131-56), adquire tamanho rasgo de anacronismo ao ser defendida na 
aurora dos anos 2000 que o próprio Löwy acaba tendo de projetar seu fundamento último, confessadamente indemonstrável, em "um núcleo irredutível de fé,... de aposta histórica sobre o papel emancipador do proletariado, sobre sua vocação universal e redentora" (op.cit., p. 209; grifos do autor).

O presente texto explora a resposta de Pierre Bourdieu aos dilemas epistemológicos esquadrinhados por Löwy: se os pontos de vista sobre o mundo social são interessados, parciais e situados, essas propriedades não invalidam a própria pretensão a afirmar a verdade sobre esse mundo, incluindo-se a pretensão contida no enunciado de que "os pontos de vista sobre o mundo social são interessados, parciais e situados"? Existem tantos mundos sociais quantas forem as representações de mundo socialmente posicionadas? Como julgar a validade de pretensões distintas e frequentemente antagônicas ao conhecimento verdadeiro sobre o universo societário, considerando-se a aparente ausência de juízes que não sejam, eles próprios, partes interessadas na disputa pelo monopólio da representação legítima da realidade socio-histórica?

De Marx e Engels (1974) até epistemólogas feministas como Sandra Harding (1996) e Donna Haraway (1988), passando por Lukács (2003) e Mannheim (1960 [1936]), o fato de que os "pontos de vista" sobre o mundo social são "vistas a partir de um ponto" (Bourdieu; Wacquant, 1992, p. 74) particular desse mesmo mundo tem sido enfatizado por diversas perspectivas. Debruçando-se sobre as condições de possibilidade de um saber genuíno acerca da vida societária, tais teorizações são obrigadas a confrontar o caráter social e historicamente posicionado do sujeito cognoscente nas ciências humanas:

a) Quais são as principais influências posicionais sobre o sujeito cognoscente? Classe? Raça? Gênero? Sexualidade? Postos no campo acadêmi$\mathrm{co}$ ? 
b) Que mecanismos sociopsicológicos respondem pelos vínculos entre visões do mundo coletivo e posições particulares nesse mundo? Interesses conscientes ou inconscientes derivados da posição social? Esquemas cognitivos oriundos de experiências socializadoras?

c) Qual é o status epistemológico de tais influências? Os interesses estratégicos e as "categorias de entendimento" que os cientistas sociais devem à sua posição e trajetória de socialização seriam invariavelmente obstáculos a um conhecimento fidedigno do seu objeto? Ou as visões socialmente fundadas de mundo envolvem uma distribuição desigual de possibilidades de cegueira e lucidez?

d) Finalmente, que consequências podemos extrair do vínculo entre posição no social e visão do social para o projeto de retratar acuradamente a realidade socio-histórica? A identificação de um ponto de vista socialmente fundado que seria dotado de horizontes epistemológicos vantajosos em relação a outros (a resposta da "standpoint epistemology" de Lukács a Harding)? A síntese "relacionista" ou "pluriperspectivista" de pontos de vista diversos possibilitada por uma intelligentsia socialmente "flutuante" (como em Mannheim)?

Vejamos como Bourdieu enfrenta essas questões, desembocando em uma concepção de objetividade calcada no controle reflexivo de vieses posicionais através da "auto-objetivação" sociológica.

\section{Pontos de vista como vistas de pontos}

Segundo Bourdieu, o condicionamento posicional dos modos de apreensão do social opera tanto na dimensão cognitiva quanto na dimensão volitiva da subjetividade (Bourdieu, 2001a, p.18). Em outras palavras, as disposições intelectuais moldadas por uma trajetória posicionada no mundo social são tanto da ordem do entendimento (e.g. esquemas de 
percepção, formas de classificação) quanto da vontade (e.g. interesses estratégicos, simpatias e antipatias, preferências e aversões). Bourdieu aponta que as mais variadas etapas da pesquisa sobre a realidade societal - escolha do tema, formulação de problemáticas, referencial conceitual, métodos e técnicas utilizados etc. - são infiltradas pelas disposições subjetivas de um habitus associado à socialização do pesquisador ao longo de coordenadas de classe, etnicidade, gênero, sexualidade e assim por diante. A ênfase bourdieusiana sobre o caráter infradiscursivo do habitus (1983, p. 46) chama a atenção para o feitio difusamente vivido de tais propensões do intelecto, as quais, muitas vezes, mesmo entre os profissionais do saber discursivo, se impõem primeiramente sob a forma de estados de ânimo (simpatias e antipatias, atrações e repulsões) que apenas encontram suas justificações racional-discursivas a posteriori (2005, p. 55-6).

Oferecendo uma tipologia de tais condicionamentos, Bourdieu retraça-os a três categorias. Em primeiro lugar, os pressupostos associados à socialização no espaço social mais amplo, os quais incluem traços de classe, raça e gênero por exemplo (Bourdieu, 1989a, p. 138). O selo do pertencimento às frações de classe mais abastadas do espaço social revela-se no fato de que a participação nos "jogos (sérios) do espírito" que marcam a atividade intelectual depende de um distanciamento de necessidades econômicas urgentes (Bourdieu, 2007, p. 243). Além disso, a entrada em campos de produção simbólica como a arte, a ciência ou a filosofia é favorecida pela aquisição prévia de um capital cultural associado às socializações familiar e escolar características de uma posição de classe (Bourdieu, 2001b, p. 134). Quanto às socializações de gênero, por sua feita, Bourdieu discerne a existência de desigualdades de poder e prestígio entre diferentes disciplinas e subdisciplinas imbuídas com marcações simbólicas "femininas" e "masculinas", mesmo em um contexto de crescimento nas oportunidades de acesso e nos índices de repre- 
sentação de mulheres nos espaços escolares em geral e acadêmicos em particular (Bourdieu, 2001a, p. 110). Quanto à dimensão racial, embora sua obra contenha diversas discussões empíricas do racismo, que vão dos seus primeiros escritos sobre a dominação francesa na Argélia (Bourdieu, 2013) até suas intervenções políticas sobre a situação dos imigrantes na Europa da década de 1990 (Bourdieu, 1998), ela não possui uma discussão teórico-geral sobre a raça como princípio de "regionalização" do espaço social.

A segunda gama de pressupostos cognitivos destacada por Bourdieu refere-se àqueles que um pensador deve à sua participação em determinado campo de produção simbólica (por exemplo, filosófico ou artístico), os quais incluem tanto as crenças constitutivas da doxa própria àquele jogo quanto aquelas atadas à posição particular do pensador nas relações internas ao campo. Em qualquer momento histórico, um campo de produção intelectual constitui um sistema de posições não apenas diferentes, mas diferenciais, isto é, definidas umas com relação às outras (Bourdieu, 2003, p. 119-26). Segundo uma associação entre posições objetivas e disposições subjetivas, válida para o conjunto dos campos, as visões de autores diversos no seio do campo conectam-se às suas divisões internas, relacionadas à posse desigual do capital de autoridade e legitimidade simbólicas específico ao campo. Em outras palavras, defender tal ou qual perspectiva em um campo de produção cultural é simultaneamente buscar uma posição de poder naquele espaço.

$\mathrm{O}$ acento sobre os campos de produção cultural na moldagem dos pontos de vista intelectuais é um tropo comum na crítica de Bourdieu a abordagens marxistas, que ele julga culpadas de estabelecer uma conexão demasiado direta ("curto-circuito" [Bourdieu, 1989a, p. 13]) entre produtos intelectuais e posicionamentos de classe (Bourdieu, 1990, p. 115). Segundo o sociólogo francês, mesmo as influências ideológicas de 
classe (assim como aquelas oriundas de outras propriedades que perpassam o espaço social e seus diferentes campos, como gênero e raça) só se exercem sobre produções culturais de modo mediado, passando por uma "refração" exercida pelo campo como tal e pela posição particular do produtor no seu interior. Com efeito, o trabalho de Bourdieu sobre "A ontologia política de Martin Heidegger" (1989b), mais do que uma intervenção nas discussões encarniçadas acerca dos vínculos entre a filosofia do autor alemão e seu engajamento político pró-nazista, é um estudo de caso acerca desse fenômeno de "refração" - casu quo, um exame de como motivos ideológicos relacionados à "revolução conservadora" na Europa do tempo de Heidegger puderam encontrar, na sua obra, uma expressão particular ao campo filosófico, graças à tradução sistemática daqueles motivos nos termos das problemáticas, das referências e dos vocábulos tidos como legítimos naquele campo. Longe de derivar do cálculo explícito, essa tradução filosófica de orientações político-ideológicas que Heidegger partilhava com autores como Spengler e Jünger teria sido efeito de um habitus intelectual constituído no próprio campo filosófico; portanto, capaz de pensar espontaneamente nos termos consagrados pela sua história (Bourdieu, 2003, p. 124-25).

Finalmente, Bourdieu devota muitas de suas páginas às propensões cognitivas derivadas da situação de skholè ou otium inerente ao ofício do intelectual: a liberdade frente a pressões urgentes do mundo, a qual possibilita uma postura contemplativa diante dele e, assim, a própria existência dos campos de produção erudita (Bourdieu, 2001a). Como quaisquer outras disposições subjetivas, a dedicação a empreitadas intelectuais pelo homo scholasticus depende da instauração de certos ambientes sociais nesse caso, aqueles que tornam possível uma atitude de contemplação do real, devidamente insulada das pressões da necessidade material e das urgências da prática cotidiana. Quando inconscientes quanto às limitações 
epistemológicas oriundas dessa situação socialmente excepcional, intelectuais tendem, inadvertidamente, a projetar sua relação contemplativa com o mundo nos próprios agentes que estudam. A principal manifestação desse "erro escolástico", endêmico na filosofia e nas ciências sociais, consiste nas caracterizações intelectualistas das motivações do agente humano - por exemplo, nas teorias que fazem a ação remontar a um cálculo explícito de alternativas de conduta ou à obediência consciente a normas coletivas (Bourdieu; Wacquant, 1992, p. 123).

\section{Instrumentos sociológicos de auto-objetivação; ou galhos e cipós para sair do pântano}

O reconhecimento desses condicionamentos socioestruturais que pesam sobre as visões de mundo de pesquisadores não leva Bourdieu ao relativismo epistemológico, isto é, a reduzir a validade dos produtos intelectuais, necessária e/ou completamente, às disposições implicadas nas localizações objetivas de seus produtores. O sociólogo francês também não abraça qualquer espécie de "standpoint epistemology" (Harding, 1996) segundo a qual certas posições estruturais seriam mais conducentes à lucidez sociológica do que outras. Em vez disso, sua proposta epistêmica retoma o compromisso com o controle metódico dos condicionamentos "libidinais" (lato sensu) e cognitivos que influenciam a atividade sociocientífica. No entanto, longe de reduzir tal controle à sinceridade de intenções ou ao mero esforço psicológico, Bourdieu propõe que ele advenha de uma objetivação sociológica das próprias condições socio-históricas de produção da sociologia (Bourdieu, 1990, p. 114).

Tal como Löwy, Bourdieu delineia um caminho de aquisição da objetividade científica que não se baseia na exortação psicologista ao autocontrole que inspirou, no primeiro, a divertida analogia münchhau- 
seniana. A ideia mesma de que os pressupostos cognitivos que devemos à nossa trajetória de socialização, os quais estruturam impensadamente nossa percepção do mundo, poderiam ser acessados e controlados pela mera introspecção é lida por Bourdieu como sintoma magno do que ele denominou de visão escolástica: "a ilusão da onipotência do pensamento", tentação contínua (para não dizer síndrome ocupacional) dos intelectuais (Bourdieu, 2001a, p. 19). Em vez disso, ele propõe uma análise sociológica dos determinantes socio-históricos que pesam sobre a própria sociologia, procedimento pensado como conducente a uma margem de liberdade possível em relação àqueles determinantes. Buscando distinguir sua modalidade de reflexividade sociológica da frouxa evocação intimista de vivências sociais, Bourdieu defendeu que as armadilhas da introspecção tinham de ser combatidas com todos os instrumentos de objetivação disponibilizados pela ciência social, tais como o levantamento estatístico, a investigação histórica e o registro etnográfico (op. cit., p. 20).

Longe de cingir-se, por assim dizer, ao domínio exterior à pele do pesquisador, tal "objetivação do sujeito da objetivação" (Bourdieu, 1990, p. 114) buscaria acessar, a partir de sua posição e trajetória no espaço societário, os seus pressupostos mais profundos de visão e intelecção do mundo social, tomados como traços desse mesmo mundo internalizados na sua subjetividade via socialização. A objetivação reflexiva de si que o sujeito cognoscente leva a cabo dirige-se, assim, ao conjunto das coações que moldam suas percepções mais ou menos espontâneas do mundo social, coações ao mesmo tempo objetivas (por exemplo, o grau de capital específico associado a uma posição no campo acadêmico) e subjetivas (p. ex., os esquemas cognitivos e interesses estratégicos atrelados à sua posição e tornados disposições). Foi com base nessas premissas epistemológicas que Bourdieu levou a cabo, sobretudo em Homo Academicus (2011), um estudo do próprio campo intelectual de forças e lutas em que ele estava imerso como um agente interessado. 
Segundo Bourdieu, tal objetivação dos pressupostos e limites, propensões e vieses, lacunas e parcialidades do seu pensamento ofereceria ao cientista social a chance de transcendê-los ao menos em certa medida, incrementando, assim, o grau de validade objetiva dos seus retratos de tal ou qual fenômeno societário. No que toca ao "problema de Münchhausen", uma vez que a auto-objetivação sociocientífica propugnada por Bourdieu não recorre à mera autoexploração ou à apologia das boas intenções epistemológicas, mas a uma explicação-compreensão sociológica de si, ele poderia sublinhar que os instrumentos de objetivação acumulados pela história da ciência social são como cipós ou galhos de árvores nos quais o estudioso pode se agarrar para escapar ao pântano de seus preconceitos sociocognitivos:

Tomar a inserção social do pesquisador como um obstáculo insuperável para a construção de uma sociologia científica é esquecer que o sociólogo encontra armas contra as determinações sociais na própria ciência que as ilumina, e portanto em sua consciência (Bourdieu, 1988, pp. 5-6).

\section{A crítica à sociologia "bourdivina"}

Segundo vários de seus críticos, há uma tensão inerente aos apelos de Bourdieu em prol da reflexividade como ferramenta metodológica que permitiria a conquista da objetividade nas ciências sociais. De um lado, temos sua insistência de que as afirmações que ele faz acerca dos agentes no campo intelectual que o envolve, na medida em que advêm de um agente posicionado nesse mesmo campo, se aplicariam também a ele (2001a, p. 145). Segundo postula sua própria caracterização da lógica dos campos, suas intervenções no debate sociocientífico seriam manobras interessadas na acumulação e na manutenção de um capital de autoridade e prestígio ali possuídos. Ao defender que a sociologia da sociologia não 
constitua uma especialidade no campo, mas seja praticada como elemento constitutivo de qualquer saber científico-social digno desse qualificativo, Bourdieu, segundo rezaria um retrato calcado na própria economia bourdieusiana das trocas acadêmicas, propõe a concepção de cientificidade mais afeita aos seus próprios interesses estratégicos. Naturalmente, ele replicaria que a objetivação sociológica do espaço total de posições em termos dos quais se delineiam os interesses dos agentes no campo intelectual, inclusive os seus próprios, é precisamente o que possibilitaria a ele controlar os "efeitos de posição" que pesam sobre seu modus cognoscendi (1988, p. 6). Entre os não praticantes da sociologia da sociologia, a inconsciência quanto a tais determinações estruturais é o que permitiria, por outro lado, que elas se exercessem de maneira mais intensa e incontrolada sobre as suas "tomadas de posição" (prises de positions).

A suspeição epistemológica que Bourdieu estende aos seus colegas-competidores no campo, ao ressaltar o caráter estratégico e interessado das suas posturas intelectuais, poderia, no entanto, ser de novo devolvida a ele: sustentar que a objetivação sociológica dos seus interesses de posição o permite transcender, ao menos parcialmente, as distorções cognitivas produzidas por tais interesses não é avançar uma proposição interessada? Bourdieu agora responde com a afirmação de que seu uso da sociologia do conhecimento sociológico não é "cínico", mas "Clínico" (1996b) - uma distinção que, como bem viu Vandenberghe (2010, p. 7678), ecoa uma anterior diferenciação mannheimiana entre as concepções "particular" e "total" de ideologia (Mannheim, 1960 [1936], p. 67). Em ambos os casos, o que está em jogo é a diferença entre uma objetivação radical dos rivais intelectuais que funciona como estratégia de desqualificação de suas afirmações (e.g. "toda a sociologia weberiana é uma resposta burguesa a Marx"), de um lado, e um diagnóstico do espaço social total de pontos de vista nos quais o próprio analista está posicionado, 
de outro (diferentemente de Mannheim, entretanto, o alvo primordial da objetivação sociológica proposta por Bourdieu é o jogo específico de produção cultural no qual os cientistas sociais estão engajados). Mas seus críticos retrucariam que a intenção "clínica" é inconsistente com o que Bourdieu afirma a respeito das condutas de seus colegas:

[...] esse movimento bachelardiano pelo qual o autor de Homo Academicus tenta criar uma terceira posição para ele mesmo é...problemático,...porque ele próprio afirmou... que não há, e não poderia haver, uma posição independente sobre o campo advinda do interior do próprio campo. Em segundo lugar, a aplicação reflexiva da sua...sociologia à sua...sociologia desmascara sua posição epistemológica como uma posição ideológica e, assim, como um movimento interno ao próprio campo (Vandenberghe, 2010, p. 79).

Como vimos, Bourdieu sustenta que as parcialidades dos pontos de vista sociocientíficos sobre o mundo social não são apenas da ordem da vontade (interesses estratégicos), mas também do entendimento (esquemas cognitivos de apreensão). Para vários de seus críticos, a tensão acima mencionada entre o reconhecimento de sua imanência ao campo, de um lado, e sua intenção de transcendência das parcialidades que afetam os demais jogadores, de outro, se aplica também ao domínio cognitivo:

como pode ele ter acesso à posição de "espectador imparcial", observando suas próprias observações e aquelas dos outros, vendo o que eles não veem e talvez até o que ele não vê? (...)...este parece ser o ponto em que a sociologia bourdieusiana torna-se "sociologia bourdivina" (Vandenberghe, 2010, p. 80).

[a] objetivação tem de ser feita no interior do espaço "reconstruído" pelo próprio Bourdieu, o objetivador "particular". (...) Se reconstruído por outros que ocupam posições diferentes no campo, uma série de retratos ou histórias radicalmente diferentes da estrutura e da evolução do campo emergirão (Kim, 2010, p. 749) 
O próprio projeto bourdieusiano de representação científica do mundo social, que recai regularmente em um discurso convencional de realidade e em uma postura holística de transcendência. (...) Bourdieu...toma cuidado em se incluir no retrato sociológico; mas ainda é Bourdieu que estabelece as condições explanatórias e define os parâmetros...no seio dos quais ele posiciona "objetivamente" a si mesmo e aos outros. (...)...isto pressupõe...um privilégio prévio à própria teoria da ciência como campo de Bourdieu (Pels, 2003, p. 173)

Conforme esse eixo de críticas, a tese de Bourdieu segundo a qual a objetividade de sua caracterização do mundo social é possibilitada por sua auto-objetivação seria circular, já que sua auto-objetivação já pressuporia, de saída, a verdade daquela caracterização do mundo social. Em justiça ao sociólogo francês, vale dizer, no entanto, que esse dilema da "petição de princípio" afeta todas as perspectivas que buscam compatibilizar a pretensão à objetividade com o reconhecimento do caráter socialmente posicionado de qualquer visão sobre a vida social. Nas discussões sobre "saberes situados" (Haraway, 1988), por exemplo, a afirmação de que qualquer ponto de vista sobre o mundo social é condicionado pela "localização" do seu observador assume inevitavelmente um compromisso ontológico prévio com uma caracterização do que são pontos de vista sobre o mundo social, bem como dos modos pelos quais o segundo impacta os primeiros (Pels, 2003, p. 156). Essa circularidade já afligia a principal matriz das "epistemologias do ponto de vista" (standpoint epistemologies [Harding, 1996]) nas ciências sociais, isto é, a tese lukácsiana do privilégio epistemológico de uma perspectiva identificada à "consciência de classe" do proletariado (2003) ${ }^{1}$. O marxista húngaro - assim como Löwy depois dele (2000, p. 127-33) - busca fundamentar tal superioridade epistêmica com um retrato substantivo dos horizontes socio-históricos de consciência

1 Lukács não se refere necessariamente à consciência empírica discernível nas mentes dos proletários em qualquer momento dado, mas à consciência que pode ser "adjudicada" ou "imputada" ao proletariado como o sentido histórico de sua condição (Lukács, 2003, p. 179). 
Sociologias, Porto Alegre, ano 19, no 45, mai/ago 2017, p. 336-369

de classe sob o capitalismo². Tal retrato não poderia ser defendido, no entanto, com base na tese de que ele exprime a lucidez da consciência de classe do proletariado, pois essa mesma lucidez está sendo afirmada a partir daquele retrato. Nos termos concisos de Eagleton: "afirmar que apenas a perspectiva proletária permite que se capte a verdade da sociedade como um todo já assume que se sabe o que é a verdade"3 (1991, p. 97).

O acento sobre a falácia da petição de princípio no vínculo que Bourdieu estabelece entre objetividade e auto-objetivação se junta frequentemente à crítica - menos interessante - à "arrogância" do seu projeto (e.g., Boltanski, 1990). Pels (2003, p. 158) sublinhou que "muitos esforços de autoclarificação podem...degenerar em uma chantagem su-

\footnotetext{
2 A abordagem do Lukács de História e Consciência de Classe (2003) lança mão de um conjunto complexo de teses para justificar a primazia epistemológica do ponto de vista do proletariado. Grosso modo, a apreensão dialética da sociedade capitalista como "totalidade" (op. cit., p.78) descobriria nela o telos da abolição do capitalismo e, portanto, do domínio de classe burguês (ainda que tal teleologia não seja pensada por Lukács em termos de leis mecânicas, mas como mediada pela práxis consciente do proletariado [op.cit., p.65-70]). Já que este desenlace corresponderia ao interesse objetivo da classe proletária e não ao da classe burguesa, a primeira teria tudo a ganhar ao descobri-lo como potencialidade no próprio movimento da história, enquanto a última estaria condenada a ocultar de si, ao menos parcialmente, as condições socio-históricas reais de sua existência (op.cit., p.146-147). No enorme capítulo sobre "a reificação e a consciência do proletariado" (op.cit., p.193), Lukács aduz ainda a ideia de que, como seres humanos que o capitalismo trata como coisas, os proletários experimentam mais direta e intensamente sua força reificadora e, assim, estão mais aptos a descobrir a reificação como essência do sistema capitalista como um todo (op.cit., p.319)

3 A despeito de suas discordâncias entre si, as tradições intelectuais que se perguntam pelos condicionantes socio-históricos do pensamento social se postam, em bloco, contra o realismo "ingênuo" de perspectivas que se pronunciam acerca do universo societário sem enfrentar, antes, a pergunta reflexiva acerca da posição a partir da qual tais pronunciamentos são feitos. Nesse âmbito, aquelas tradições sociologizam o projeto epistemológico tal como concebido na filosofia moderna desde Descartes, isto é, a tese de que que a tentativa de conhecer o real tem de ser precedida da reflexão sobre as condições e limites do conhecimento humano do real. O problema é que, para o cognoscente humano, simplesmente não há como retratar as condições de conhecimento do real sem supor que elas sejam parte...do real. A afirmação de que não se pode acessar um mundo exterior ao "jogo de linguagem", "paradigma", episteme ou "formação discursiva" em que se está enredado supõe, por exemplo, uma ontologia dessas entidades chamadas "jogo de linguagem", "paradigma", episteme e "formação discursiva". Como viram Habermas (1987, p.28) e Hamlin (2014, p.39-41), o problema da petição de princípio na reflexão epistemológica já havia sido sublinhado por Hegel em sua crítica a Kant.
} 
til...na medida em que a autoexposição do observador vem com uma prerrogativa política de expor as autocontradições do observado" (Pels, 2003, p. 158). A passagem descreve bem como a sociologia reflexiva de Bourdieu veio a ser vista em diversos quartéis: graças ao "blefe" da objetivação sociológica de suas próprias limitações de perspectiva, a sociologia bourdivina poderia reclamar para si a capacidade de alcançar "a famosa visão a partir de lugar nenhum que é a de Deus" (Latour, 2005, p. 139), a mesma visão que ela nega a todos os demais. Tendo provado, em Homo Academicus, que ele era mais inteligente do que todos os seus pares acadêmicos, Bourdieu ofereceu, então, seu Esboço de autoanálise (2005) para provar que era mais inteligente do que ele mesmo. E assim seguem as ironias...

Possivelmente sob o impacto dessas críticas, Bourdieu, nos momentos mais tardios da sua carreira, passou a combinar a ênfase sobre a auto-objetivação como empreitada de um pesquisador singular com uma noção de objetividade como efeito relacional e emergente da lógica do campo científico. Nesse sentido, antes de prosseguirmos na discussão sobre a objetividade nas ciências sociais, precisamos passar pela caracterização bourdieusiana das condições da objetividade em toda e qualquer ciência, caracterização formulada sobretudo em Meditações pascalianas (2001a [1997]) e Ciência da ciência e reflexividade (2004 [2001]).

\section{O campo científico}

Tal qual sua sociologia de outros campos, como o artístico ou o religioso, a análise bourdieusiana do campo científico dirige-se tanto aos caracteres gerais que ele compartilha com outros em termos de "estrutura e funcionamento" (Bourdieu, 1988, p. 44) quanto ao que o singulariza em face de campos distintos. $\mathrm{O}$ veio da semelhança conecta-se à des- 
mistificação das noções clássicas da atividade científica como exceção à lei da ação interessada que Bourdieu postula na teoria dos campos e na "economia geral das práticas" (1977, p. 177). O veio diferenciador de sua concepção do cosmo científico sublinha, por sua feita, a especificidade dos interesses e lucros que movem os atores ali, levando-os a "desinteressar-se", em boa medida, por móbeis como dinheiro e poder político. Assim como os campos artístico e religioso, o campo científico é movido pela disputa em torno de uma forma específica de capital simbólico, manifesta nos certificados de "glória, honra, crédito, reputação, notoriedade" (Bourdieu, 2001a, p. 202) que legitimam o exercício da autoridade naquela esfera de atividade.

Ainda como naqueles campos, as estratégias mobilizadas na disputa pelo capital específico enraízam-se sobretudo na distribuição desigual de tal capital entre agentes dominantes e dominados (Bourdieu, 2003, p. 119-26). Dotados de maior volume de capital científico acumulado, os primeiros tendem a cultivar estratégias de conservação do status quo que os favorece. Por sua feita, o grupo de dominados inclui tanto os marginalizados pelos critérios vigentes de acumulação dos lucros simbólicos do trabalho científico quanto os agentes mais ou menos recém-chegados ao campo. Aos últimos, cabe a escolha entre estratégias ortodoxas de sucessão dos dominantes ou o caminho mais arriscado de tentativas de subversão do estado de coisas vigente. Embora o confronto entre estratégias ortodoxas e heterodoxas se desenrole contra o pano de fundo da doxa compartilhada, as lutas simbólicas entre os grupos dominantes e dominados se estendem à própria concepção de como uma disciplina científica deve ser conduzida e, portanto, às fronteiras que vigem no campo (Bourdieu; Wacquant, 1992, p. 184).

A singularidade da perspectiva de Bourdieu sobre a ciência deriva de sua tentativa de compatibilizar duas teses vistas amiúde como incompatí- 
veis: o reconhecimento do caráter "interessado" da atividade científica e a ideia de que tal atividade engendra produtos intelectuais objetivamente válidos, isto é, irredutíveis aos interesses particulares daqueles que os geraram. O sociólogo francês combinou o diagnóstico das competições que animam o "mercado de bens científicos" (Bourdieu, 1983, p. 133) com a tese de que as leis socio-históricas imanentes à ciência forçam os cientistas individuais a perseguirem seus interesses privados na acumulação de capital simbólico somente através de contribuições públicas, impessoais, para um empreendimento coletivo. Dessa forma, Bourdieu manteve seu retrato das lutas aguerridamente autointeressadas pelo capital científico, em contraste com quaisquer imagens ingênuas de cientistas desinteressados, sem, no entanto, negar a validade objetiva e universal dos produtos intelectuais que resultam de tais lutas históricas ("vícios privados, benefícios públicos", como reza a Fábula das Abelhas de Mandeville). Seu "racionalismo historicista" (Bourdieu, 2001a, p. 148), que tanto explica quanto justifica a ciência como uma "Realpolitik da razão" (Bourdieu; Wacquant, 1992, p. 190), procura, portanto, escapar a qualquer transcendentalismo a-sociológico no mesmo passo em que evita, digamos, o agnosticismo epistemológico de Foucault (Merquior, 1985, p. 146-7) ou o "niilismo subjetivista" das etnografias da ciência de Latour e Woolgar (Bourdieu, 2004, p. 26-31).

Em outras palavras, Bourdieu buscou escapar tanto às formas a-históricas do racionalismo quanto às consequências relativistas de estudos da ciência como atividade socio-histórica. O modelo bourdieusiano da "Cidade Científica" (Bourdieu; Wacquant, 1992, p. 178), primeiramente extraído de uma história sociológica da ciência e posteriormente convertido em ideal normativo, situa a razão não na estrutura da mente humana (à la Kant) ou da comunicação linguística (à la Habermas), mas no tipo de diálogo não violento que aquela Cidade institui. Com seu típico trilhar de 
uma via sintética para além das dicotomias reinantes entre os seus coetâneos, seu historicismo racionalista defende a validade universal dos enunciados científicos, mas sustenta que tal atributo é tornado possível não por quaisquer fundamentos transcendentais do conhecimento humano, e sim por condições socio-históricas particulares e contingentes - grosso modo, aquelas que ensejaram a emergência e a consolidação (sempre ameaçada) da ciência como microcosmo autônomo de atividade. Em compasso com a dialética entre instituições e corpos que Bourdieu observaria em outras esferas da vida social (1988, p. 40) a cristalização histórica do campo científico como instância de atividade substancialmente autônoma em relação a constrições exteriores (por exemplo, pressões de natureza financeira ou política) caminhou a par e passo com o cultivo de interesses e competências especificamente voltados aos lucros simbólicos deste campo em detrimento dos demais. $\mathrm{O}$ interesse específico do cientista passa a significar, assim, desinteresse pelos bens vulgarmente associados à noção de conduta interessada, como dinheiro e poder político - daí a noção provocativamente paradoxal de "interesse pelo desinteresse" (Bourdieu, 2001a, p. 246).

No entanto, longe de reduzir os produtos intelectuais engendrados pelos cientistas a meras expressões de seus interesses particulares, a ciência, pelo menos nas suas modalidades mais autônomas, logrou institucionalizar um mecanismo "alquímico" de conversão de vontades privadas em benefícios públicos. A operação de regras impessoais de discussão e de confronto de ideias, de verificação e de crítica mútua, faz com que os lucros próprios ao campo científico, tais como o capital simbólico de prestígio e autoridade apropriados por um indivíduo ou uma instituição particular, só possam ser alcançados ao preço de uma contribuição intelectual capaz de sobreviver ao crivo daquelas regras e, portanto, de beneficiar a ciência como empreitada coletiva: 
Esses universos fundados na skholè e na distância escolástica em relação à necessidade e à urgência, sobretudo econômicas, favorecem trocas sociais em que os constrangimentos sociais assumem a forma de constrangimentos lógicos (e vice-versa). Mesmo quando favoráveis ao desenvolvimento da razão, tal ocorre porque é preciso fazer valer razões, para que se possa aí fazer valer; assim como para triunfar neles, é preciso fazer triunfar neles argumentos, demonstrações ou refutações. Os "móbiles patológicos" a que se refere Kant... somente podem se tornar eficazes nesses universos contanto que se ajustem às regras do diálogo metódico e da crítica generalizada (Bourdieu, 2001a, p. 132-3).

Segundo Bourdieu, são estes mecanismos institucionais de regulação da comunicação e de checagem recíproca que propelem o progresso do conhecimento universalmente válido no campo científico. Ao tomar a competição entre agentes autointeressados como sua base, institucionalizando-a de maneira tal que a busca de lucros simbólicos particulares só possa ocorrer sob a forma sublimada de reivindicações publicamente averiguáveis de validade, o campo científico faz florescer um mecanismo de universalização bem mais poderoso, segundo Bourdieu, do que quaisquer exortações moralizantes à visão imparcial e à neutralidade axiológica. É tal mecanismo que não apenas descola os enunciados produzidos por cientistas interessados nas recompensas do campo daquilo que aqueles devem aos interesses particulares destes cientistas, mas, de modo mais amplo, gera, no seio da história, "verdades irredutíveis à história" (Bourdieu, 2001a, p. 132).

A sublimação da libido dominandi de agentes particulares em uma libido sciendi forçada a utilizar somente as armas de luta apropriadas à lógica do campo científico, tais como a demonstração lógica e a verificação empírica, é tanto maior quanto maior for a autonomia de que tal campo goza. A condição mesma de produção de verdades científicas é a prevenção da utilização de princípios heterônomos ao campo científi- 
co, tais quais incentivos pecuniários ou pressões políticas, como armas de competição no seu interior. Além disso, o crescimento cumulativo do saber produzido no seio do campo, ao tornar mais custosos seus preços de entrada, também significa uma redução drástica na audiência dos produtos intelectuais ali veiculados, audiência que passa a identificar-se, cada vez mais, com outros produtores dotados da perícia necessária para decifrá-los a avaliá-los. Isto cria uma situação de vigilância cognitiva em que os avaliadores críticos dos produtos simbólicos que lá circulam são outros produtores, isto é, rivais.

É a partir desse argumento que Bourdieu responde à acusação de que, ao defender que sua intenção objetivante é clínica em vez de cínica, ele se eximiria do diagnóstico sociológico de autointeresse que ele estende ao conjunto dos seus colegas. Em compasso com sua visão do progresso da ciência como produto emergente do cenário social de competição entre agentes individuais submetidos às suas normas e demandas, ele agora diz que o "geometral de todas as perspectivas" (Leibniz), o ponto de vista "de lugar nenhum" (Nagel) e de todos os lugares, em suma, a vista de Deus não seria, nas ciências sociais, aquela de qualquer agente particular situado no campo, mas a do campo mesmo - nesse caso, de uma lógica de auto-objetivações e objetivações recíprocas:

Ninguém pode forjar armas suscetíveis de serem utilizadas contra seus adversários sem ficar exposto a que essas armas se voltem de imediato contra si, aplicadas tanto pelos adversários como por outros, e assim sucessivamente, ao infinito. É dessa lógica propriamente social, e não de alguma deontologia ilusória e farisaica, que se pode esperar algum progresso em direção a uma reflexividade maior, imposto pelos efeitos da mútua objetivação e não por um simples retorno, mais ou menos narcisista, das subjetividades sobre si mesmas (Bourdieu, 2001a, p. 145).

Contra aquelas críticas que supõem que Bourdieu pretende falar pelo campo, ele enfatizaria tal caráter social da reflexividade como arma 
científica. A objetividade do conhecimento científico-social não seria resultado apenas da auto-objetivação levada a cabo por um único cientista social, mas um efeito das objetivações mútuas instauradas pelo campo, bem como da autovigilância inculcada pelo senso que cada participante do jogo tem quanto à possibilidade de ter a si e às suas produções simbólicas submetidos à objetivação. O caráter "clínico" da sociologia reflexiva derivaria "dessa lógica propriamente social [...] da mútua objetivação", não de alguma "deontologia ilusória e farisaica" capaz de neutralizar a dimensão autointeressada do exercício objetivante:

O fato de que produtores tendam a ter como seus clientes apenas os seus competidores mais rigorosos e vigorosos,... aqueles...mais inclinados e mais capazes de dar à sua crítica força plena, é...o ponto arquimediano no qual podemos nos apoiar para dar uma caracterização científica da razão científica, para resgatar a razão científica da redução relativista e explicar como a ciência pode progredir...na direção de maior racionalidade sem ter de apelar para alguma espécie de milagre fundador (Bourdieu, 2004, p. 54).

\section{Bourdieu, o idealista}

Bourdieu se esforça por apresentar sua análise do campo científico como uma explicação-e-justificação da validade universal dos enunciados da ciência que não resvala para a idealização das motivações dos cientistas - à maneira, digamos, da clássica peça de Merton (1973, p. 577-98) sobre os valores da comunidade científica ${ }^{4}$. Não obstante, o retrato bour-

\footnotetext{
${ }^{4}$ A consulta a outros textos de sociologia histórica da ciência da lavra de Merton (1973) mostra, entretanto, que, longe de abraçar uma visão rósea dos motores subjetivos das práticas científicas, ele estava bastante ciente do que estas possuíam de autointeressadas e aguerridamente competitivas. O próprio Bourdieu veio a reconhecer, em Ciência da ciência e reflexividade (2004, p.12-13), que seu texto de 1975 sobre o campo científico (1983, p.130) não tratou as visões de Merton com a devida justeza.
} 
dieusiano, dos resultados de práticas científicas interessadas como fundados em um mecanismo institucional de conversão - ou "sublimação" - de interesses particulares em conquistas de interesse universal, possui, ainda assim, afirmam seus críticos, um "resíduo de idealismo racionalista" (e.g., Pels, 2003, p. 120). Por um lado, Bourdieu reconhece que seu raciocínio passa de uma descrição da produção socio-histórica de verdades científicas a um conjunto de prescrições derivadas de tal descrição, associadas, naturalmente, a uma apreciação de valor positiva quanto ao significado cultural e mesmo civilizacional da ciência. Por outro lado, embora Bourdieu apresente a sequência de seu argumento em termos de descrição-valorização-prescrição, vários de seus intérpretes (e.g., Schatzki, 2006, p. 499) julgam que sua caracterização substantiva do mundo científico é, de saída, tutelada por seus compromissos normativos com a manutenção das condições socio-históricas de possibilidade da ciência, as quais Bourdieu (2004, p. vii) percebia como crescentemente ameaçadas (por exemplo, pelas perturbações à autonomia do campo científico oriundas de interesses mercadológicos). Segundo esses críticos, a despeito de não deslizar para a idealização das motivações dos cientistas, sua pintura dos mecanismos de sublimação de paixões autointeressadas sob a forma de diálogos racionais que culminam na "força do melhor argumento" (Habermas) - ou na "força intrínseca da ideia verdadeira" (Spinoza) ou na "força da razão" (Kant) não escaparia à idealização: "a natureza quase popperiana e quase habermasiana do campo científico tal como esboçado...[por Bourdieu] parecerá a muitos boa demais para ser verdade" ${ }^{5}$ (Inglis, 2005, p. 378).

A contraparte dessa idealização seria sua negligência quanto aos potenciais efeitos destrutivos de uma realpolitik da razão e de uma cor-

5 Como reconheceu o próprio Bourdieu (2004, p.82-83), ao salientar que a objetividade depende crucialmente, tanto nas ciências naturais quanto nas ciências sociais, dos controles intersubjetivos institucionalizados pelo funcionamento do(s) campo(s) científico(s), sua perspectiva ecoa argumentos avançados por Popper algumas décadas antes (p.ex., Popper, 1957, p.155). 
poração autônoma de intelectuais, os quais podem incluir desde o favorecimento "clientelista" na distribuição de postos de autoridade acadêmica até a superprodução de refugo bibliográfico. Ao empunhar a bandeira da restrição da participação no mercado dos bens científicos a colegas-competidores, Bourdieu tinha em mente as ameaças à autonomia da ciência postas por interesses heterônomos como os do grande empresariado (e.g. a tutela de estudos de neuropsiquiatria por companhias farmacêuticas), de autoridades estatais (e.g. o favorecimento de formas tecnocráticas de conhecimento social em detrimento de abordagens críticas) ou do mainstream midiático (e.g. a tentação dos holofotes levando alguns intelectuais ao abandono dos rigores científicos em favor do "fast thinking" opinioso [Bourdieu, 1996b, p. 38]). Centrando-se nas ameaças extrínsecas à autonomia do campo científico, Bourdieu termina passando ao largo, no entanto, das ameaças intelectuais e ético-políticas oriundas da autonomia do campo científico, isto é, da existência de uma corporação de cientistas eximidos de prestar contas a quaisquer outras instâncias além dos demais integrantes do mesmo campo. Quaisquer que sejam os problemas da sociologia da "sociedade de risco" (2010 [1986]) desenhada por Ulrich Beck, por exemplo, ela é certamente bem-sucedida em esquadrinhar a presença daquelas ameaças não apenas à luz de experimentos mentais da imaginação distópica, mas também das lições concretas da história recente (e.g., o acidente da usina de Chernobyl no mesmo ano em que o livro de Beck veio a lume). Assim como as propostas de instauração de vias de comunicação aberta e democrática entre peritos e leigos lançadas por outros autores (e.g., Feenberg, 1999), a visão de Beck tem ainda o mérito de delinear, pace Bourdieu, os riscos do domínio inquestionado de especialistas ("epistemocracia") sem recair, no entanto, nos excessos "anarquistas pós-modernos" de uma crítica da ciência à la Feyerabend (1987). 
E quanto às ciências sociais? Como vimos, a ênfase sobre os efeitos emergentes produzidos pela lógica relacional do campo científico transmite-se para a própria noção de reflexividade (socio)científica propugnada por Bourdieu, que não mais se identifica à empresa solitária do intelectual autárquico. Ao contrário, ela passa a ser pensada como um empreendimento que só pode avançar coletivamente, pela verificação recíproca e pela crítica mútua (Bourdieu, 2001a, p. 9). O problema aqui é que, quando aplicado às ciências sociais, o enunciado soa mais programático do que propriamente ancorado no seu desenvolvimento histórico efetivo - e é sintomático que Bourdieu não ofereça qualquer exemplo em que a crítica mútua dos pontos de vista, atada à objetivação de suas fontes posicionais, tenha levado à refutação de falsas ideias. Uma vez mais, no entanto, o sociólogo francês teria uma explicação para essa dificuldade: a insuficiente autonomia do espaço em que se faz ciência social.

\section{Autonomia e cientificidade da sociologia}

Em compasso com sua visão da autonomia da ciência não como conquista individual, mas como efeito de certas condições socio-históricas que impedem que a distribuição de autoridade científica seja usurpada por critérios heterônomos ao campo (e.g. poder político), Bourdieu sociologiza a própria discussão sobre os obstáculos à cientificidade genuína nas ciências sociais. Segundo sua perspectiva, as dificuldades específicas que se interpõem à conquista da cientificidade na sociologia não derivam primordialmente de sua dimensão interpretativa, isto é, do fato de que elas têm de se haver com a compreensão dos significados (inter)subjetivos da conduta humana, como classicamente enfatizado por autores interpretativistas de Dilthey até Geertz. Em vez disso, essas dificuldades derivariam, sobretudo, da particular suscetibilidade da sociologia a pressões sociais 
heterônomas quanto à lógica de controles científicos estritos. Tal suscetibilidade dá testemunho da insuficiente autonomia dessa disciplina frente a constrições exteriores ao mundo científico. Aplicando à ciência social uma "lei" sociológica que ele julga valer para o conjunto dos campos de produção cultural (como a arte e a religião), Bourdieu sustenta que os agentes dominados, segundo os critérios particulares de tais campos, são frequentemente tentados a transformar sua condição pelo uso estratégico de princípios heterônomos:

A dificuldade que a ciência social experimenta em romper decisivamente com o senso comum, em estabelecer seu nomos específico, deve muito ao fato de que sempre há pessoas que, sendo cientificamente dominadas, estão espontaneamente do lado do pré-construído, que têm interesses vitais em desconstruir o construído, em desentender o entendido e...em tentar trazer todos de volta à linha de partida. Eles podem ser encontrados fora do campo, mas também dentro do campo; e aqueles que estão fora seriam bem menos influentes não fosse pelos que os auxiliam do interior (Bourdieu; Wacquant, 1992, p. 184).

Como esfera semiautônoma de produção e circulação de ideias, a ciência social congregaria as lógicas discrepantes do campo político, de um lado, e do campo científico nas suas modalidades mais autônomas, de outro. No primeiro, a força das ideias deriva sobremaneira do poder possuído pelos indivíduos e grupos que as propõem como válidas. No segundo, o poder de reconhecimento dos produtos intelectuais não derivaria de apoios extrínsecos, mas da "força intrínseca da ideia verdadeira" (Spinoza). Em contraste com as áreas mais autônomas das ciências da natureza, a incompleta autonomia do campo das ciências sociais é o que permitiria explicar que ideias há muito submetidas à desmontagem lógica e à refutação empírica permaneçam vivas e em circulação. Seu déficit de autonomia daria ensejo ao jogo duplo de intelectuais que haurem pres- 
tígio da participação no campo de produção restrita sem renunciarem a outros jogos - por exemplo, à notoriedade extra propiciada pelos comentários opiniosos sobre os "assuntos do momento" em veículos como o jornalismo e o ensaísmo cultural.

Com efeito, embora Bourdieu reconheça um continuum de graus de autonomia que impossibilita a averiguação da cientificidade da sociologia em termos de "tudo ou nada" (Bourdieu et al. 1999, p. 94), seu investimento na autonomia do campo sociocientífico tenciona uma firme demarcação entre o discurso sociológico, de um lado, e, de outro, o discurso dos "porta-vozes, homens políticos, ensaístas, jornalistas", em suma, "todos aqueles cuja profissão" é debater, "dia após dia, semana após semana", "todos os temas obrigatórios do momento, a 'juventude', a 'violência', a 'droga',... etc." (2003, p. 10). Ao fast thinking opinativo diante dos problemas da hora, a ciência social oporia um discurso submetido a controles lógicos e empíricos estritos, o qual, portanto, não pode senão ser lentamente elaborado, ao ponto de chegar frequentemente ao debate "após a luta", quando os seus contendores já estão com as vistas em outro tópico quente. À prosa facilmente compreensível, a ciência social oporia um discurso inevitavelmente complexo e propenso, assim, a desencorajar àqueles não imbuídos do gosto (ou tolerância) pela complexidade ou simplesmente do capital cultural necessário à sua decifração. Às gratificações egoicas dos holofotes midiáticos, a ciência social oporia o sacrifício de projeções pessoais pela própria natureza impessoal e abstrata do seu discurso. Finalmente, à tendência demagógica à "pregação aos convertidos", a ciência social oporia uma distância crítica diante de crenças espontâneas e impressões recebidas (Bourdieu, 2003, p. 10; Bourdieu; Wacquant, 1992, p. 187).

A defesa da autonomia da sociologia significaria abdicação de quaisquer intenções de intervenção ético-política sobre a realidade social? Longe disso. Como é sabido, Bourdieu se integra a uma tradição de teo- 
ria crítica da dominação que é sensível aos mecanismos socio-simbólicos pelos quais condições de existência historicamente contingentes são vivenciadas e reproduzidas como ordenamentos naturais e evidentes das coisas (uma tradição que vai de Marx a Judith Butler, passando por Lukács e Foucault). Uma das singularidades da versão de teoria crítica abraçada por Bourdieu, no entanto, consiste na ideia de que o potencial ético-político das ciências sociais não emerge a despeito da sua autonomia, mas por causa dela. A síntese entre autonomia e engajamento proposta por Bourdieu rejeita, nesse sentido, tanto a clausura do cientista social na torre de marfim quanto a sua tutela por atores políticos externos, como instituições governamentais e movimentos sociais. Para ele, a condição mesma de possibilidade de que o conhecimento científico-social seja investido de potência emancipatória para tais ou quais agentes no mundo societário é o fato de que o sociólogo não possua qualquer "mandato" ou "missão" além daqueles "que assume em virtude da lógica de sua pesquisa" (Bourdieu, 1988, p. 28). Apesar de suas referências à intelligentsia "sem vínculos nem raízes" teorizada por Mannheim serem invariavelmente críticas (e.g. op. cit., p. 26), Bourdieu possui em comum com o grande pensador húngaro o rechaço da orientação normativa de que intelectuais atuem como porta-vozes de classes e grupos específicos, substituída pela injunção de que eles passem a falar por si próprios enquanto estrato social. Mantendo uma relação ambivalente, misto de atração e repulsa, pela tese lukácsiana de que os interesses particulares da classe proletária como "sujeito-objeto idêntico da história" (Lukács, 2003, p. 308) coincidiam com o próprio movimento da totalidade, Mannheim havia deslocado o acesso epistemológico privilegiado à totalidade do proletariado para a intelligentsia como categoria social. Era a condição socialmente "flutuante" do intelectual que permitiria a este operar, em meio à - e para além da - pluralidade de perspectivas parciais e antagônicas, como "advoga- 
do predestinado dos interesses intelectuais do todo" (Mannheim, 1960 [1936], p. 142). O próprio Bourdieu ofereceu sua versão da coincidência entre interesses particulares e universais ao sustentar que a defesa dos privilégios associados à autonomia do campo intelectual não se reduzia ao autointeresse de uma categoria particular, pois tais privilégios já haviam se mostrado condições de possibilidade de progresso do universal. A noção provocativamente paradoxal de "corporativismo do universal" (1996a, p. 369) exprime, nesse sentido, sua tese de que a autonomia corporativa dos intelectuais seria requisito sine qua non da produção de verdades "transcorporativas", isto é, universais.

\section{Conclusão}

Enquanto a tônica dos primeiros estudos sociológicos da ciência de Bourdieu é a desmistificação da ideologia do desinteresse através da recuperação dos interesses estratégicos e práticas agonísticas que movem o "campo científico" (Bourdieu, 1983), o Bourdieu maduro de Meditações Pascalianas (2001a) e escritos afins se mostra mais preocupado em evitar potenciais implicações anticientíficas e/ou relativistas daqueles retratos sobre as conexões entre busca da verdade e lutas pelo poder. Como revela sua crítica ao recurso à heteronomia pelos dominados no campo das ciências sociais, essa reorientação o levou inclusive a fazer algo que contrastava fortemente com o restante da sua obra, isto é, a tomar o partido dos dominantes no campo ${ }^{6}$.

\footnotetext{
${ }^{6}$ O enunciado tem de ser qualificado. A condição de "dominante" não pode obviamente ser pensada em termos substancialistas, mas históricos e relacionais. Ao pronunciar-se sobre as ameaças que o grande empresariado, a burocracia estatal ou os magnatas da mídia colocam à autonomia do campo científico, Bourdieu pressupõe que os cientistas ocupam, sim, a classe dominante, mas na sua "fração dominada" (2007, p. 243) - ou, dito de outro modo, eles se inseririam no "polo dominado do campo do poder" (1996a, p. 261)
} 
Nos piores momentos, a tese de que "as ciências sociais não têm sido autônomas o suficiente para gerar a dialética racional no seu campo" (Kim, 2010, p. 5) serviu a Bourdieu como um expediente abusivo de imunização à crítica. Um exemplo é sua afirmação de que a tentação da heteronomia é o que leva cientistas sociais novatos e dominados a ressuscitarem, de modo espúrio, dicotomias que "já foram destruídas mil vezes no curso da história científica" (Bourdieu; Wacquant, 1992, p. 179), como o confronto entre objetivismo e subjetivismo. Mesmo que essa tentação seja um fenômeno real, é nítido que o argumento funcionou, por vezes, como um modo de desqualificar de antemão como "não científicas" certas críticas à sociologia de Bourdieu - por exemplo, a ideia de que sua teoria da prática não "destruiu" verdadeiramente a dicotomia objetivismo/subjetivismo, mas elaborou uma forma sofisticada de "neo-objetivismo" (Alexander, 1995; Elster, 1981).

Nos seus melhores momentos, no entanto, a reflexão de Bourdieu desemboca em um programa político-intelectual de instauração e manutenção de condições institucionais capazes de propiciar uma ciência social autônoma. Como vimos, sua concepção de autonomia rejeita uma ciência social cujo engajamento é tutelado por atores sociopolíticos externos ao campo sem, no entanto, condenar o intelectual à clausura na torre de marfim. Bourdieu também aludiu (2001c, p. 9) ao que via como errônea confusão entre "neutralidade axiológica" e "objetividade científica", sugerindo que o abandono do primeiro desiderato não invalidaria a factível busca do segundo. Embora ele mesmo não se expresse nesses termos, sugestões da sua obra indicam que, nos termos dessa distinção frequentemente negligenciada, a ideia de neutralidade axiológica referir-se-ia a um atributo psicológico do sujeito cognoscente, ao passo que a objetividade científica valeria como estatuto epistêmico de enunciados ou proposições sobre o mundo. Conforme seu retrato da "ciência como 
sublimação", são as orientações intelectuais e controles lógico-empíricos inerentes à ciência como atividade institucionalizada que tornam possível que sujeitos "subjetivos" por definição adquiram o interesse e a competência (intersubjetivamente averiguada pelos pares-rivais) que lhes permitem produzir enunciados objetivamente válidos.

Ademais, no que toca às suas implicações ético-políticas, a sociologia de Bourdieu supõe que o conhecimento do mundo social será tanto mais benéfico à ação transformadora desse mundo quanto maior for sua objetividade. Ao "sublimar" suas paixões políticas (por exemplo, o espanto diante da dominação de classe naturalizada, para ficar em apenas uma ilustração) pelo recurso aos instrumentos rigorosos do método científico, convidando ainda seus colegas a fazer o mesmo, Bourdieu não julgava estar diluindo, mas fortalecendo a potência emancipatória da sociologia, no mesmo passo em que investia na sua objetividade. Como tantos outros aspectos de seu legado, essa proposta intelectual, a despeito de suas tensões internas (ou por causa delas), ainda fala a nós com uma voz tremendamente atual.

Gabriel Peters é Doutor em Sociologia (IESP-UERJ) e professor adjunto da Universidade Federal da Bahia (UFBA), Brasil.

$\triangle$ gabrielpeters@hotmail.com

\section{Referências}

1. ALEXANDER, J. Fin de Siècle Social Theory: relativism, reduction and the problem of reason. London: Verso, 1995.

2. BECK, U. Sociedade de risco: rumo a outra modernidade. São Paulo: Editora 34, 2010 [1986].

3. BOLTANSKI, L. L'amour et la justice comme competences: trois essais de sociologie de l'action. Paris: Metaillié, 1990.

4. BOURDIEU, P. Algerian Sketches. London: Polity Press, 2013. 
5. BOURDIEU, P. Homo Academicus. Florianópolis: UFSC, 2011.

6. BOURDIEU, P. A distinção: crítica social do julgamento. São Paulo/Porto Alegre: Edusp/Zouk, 2007

7. BOURDIEU, P. Esboço de autoanálise. São Paulo: Companhia das Letras, 2005.

8. BOURDIEU, P. Science of science and reflexivity. London: Polity Press, 2004.

9. BOURDIEU, P. Questões de sociologia. Lisboa: Fim de Século, 2003.

10. BOURDIEU, P. Meditações pascalianas. Rio de Janeiro: Bertrand Brasil, 2001a.

11. BOURDIEU, P. A dominação masculina. Rio de Janeiro: Bertrand Brasil, $2001 \mathrm{~b}$.

12. BOURDIEU, P. Contrafogos 2: por um movimento social europeu. Rio de Janeiro: Jorge Zahar, 2001c.

13. BOURDIEU, P. Contrafogos 1: táticas para enfrentar a invasão neoliberal. Rio de Janeiro: Jorge Zahar, 1998.

14. BOURDIEU, P. The state nobility: elite schools in the field of power. Cambridge: Polity Press, 1996a.

15. BOURDIEU, P. Sobre a televisão. Rio de Janeiro: Jorge Zahar, $1996 \mathrm{~b}$.

16. BOURDIEU, P. Coisas ditas. São Paulo: Brasiliense, 1990.

17. BOURDIEU, P. O poder simbólico. Rio de Janeiro: Bertrand Brasil, 1989a.

18. BOURDIEU, P. A ontologia política de Martin Heidegger. Campinas: Papirus, $1989 b$.

19. BOURDIEU, P. Lições da aula. São Paulo: Ática, 1988.

20. BOURDIEU, P. Sociologia. Coleção Grandes Cientistas Sociais. ORTIZ, Renato (org.). São Paulo: Ática, 1983.

21. BOURDIEU, P. Outline of a theory of practice. Cambridge: Cambridge University Press, 1977.

22. BOURDIEU, P. et al. A profissão de sociólogo: preliminares epistemológicas. Petrópolis: Vozes, 1999.

23. BOURDIEU, P.; WACQUANT, L. An invitation to reflexive sociology. Chicago: University of Chicago Press, 1992

24. EAGLETON, T. Ideology: an introduction. London: Verso, 1991.

25. ELSTER, J. Snobs. London Review of Books, v. 3, n. 20, 1981, p.10-12. 
26. FEENBERG, A. Questioning technology. London: Routledge, 1999.

27. FEYERABEND, P. Farewell to reason. London: Verso, 1987.

28. HABERMAS, J. Conhecimento e interesse. Rio de Janeiro: Jorge Zahar, 1982.

29. HAMLIN, C. Uma hermenêutica das conversações interiores. Revista Brasileira de Sociologia, v. 2, n. 4, jun/dez 2014.

30. HARAWAY, D. Situated Knowledges: The Science Question in Feminism and the Privilege of Partial Perspective. Feminist Studies, v. 14, n. 3, p. 575-599, 1988.

31. HARDING, S. Standpoint Epistemology (a Feminist Version): How Social Disadvantage Creates Epistemic Advantage. In: TURNER, Stephen. (org.). Social Theory and Sociology: The Classics and Beyond. Cambridge: Blackwell, 1996.

32. INGLIS, D. Review of Science of science and reflexivity. European Journal of Social Theory, v. 8, n. 3, 2005, p.375-382.

33. JAY, M. Marxism and totality: the adventures of a concept from Lukács to Habermas. Berkeley/Los Angeles: University of California Press, 1984.

34. KIM, K-M. How objective is Bourdieu's participant objectivation? Qualitative Inquiry, v. 16, n. 9, p.747-56, 2010.

35. KOLAKOWSKI, L. Main currents on Marxism. Vol.3: The breakdown. Oxford: Clarendon Press, 1978.

36. LATOUR, B. Reassembling the Social: An Introduction to Actor-Network Theory. Oxford: Oxford University Press, 2005.

37. LÖWY, M. As aventuras de Karl Marx contra o Barão de Münchhausen: marxismo e positivismo na sociologia do conhecimento. São Paulo: Cortez, 2000.

38. LÖWY, M. Ideologias e ciência social: elementos para uma análise marxista. São Paulo: Cortez, 1991.

39. LUKÁCS, G. História e consciência de classe: estudos sobre a dialética marxista. São Paulo: Martins Fontes, 2003.

40. MANNHEIM, K. Ideology and utopia: an introduction to the sociology of knowledge. London: Routledge \& Keagan, [1936]1960.

41. MARX, K; ENGELS, F. A ideologia alemã. São Paulo: Paz e Terra, 1974.

42. MERQUIOR, J. G. Foucault. London: Fontana, 1985.

43. MERTON, R. The Sociology of Science: Theoretical and Empirical Investigations. Chicago: University of Chicago Press, 1973. 
44. PELS, D. Unhastening Science: Autonomy and Reflexivity in the Social Theory of Knowledge. Liverpool: Liverpool University Press, 2003.

45. POPPER, K. The poverty of historicism. Boston: Beacon Press, 1957.

46. SCHATZKI, T. Review of Science of science and reflexivity. Philosophy of the Social Sciences, v. 36, n. 4, p. 496-9, 2006.

47. VANDENBERGHE, F. Teoria social realista: um diálogo franco-britânico. Belo Horizonte: UFMG, 2010

48. VANDENBERGHE, F. A philosophical history of German sociology. London: Routledge, 2009.

Recebido: 30.12.2015

Aceite: 18.04.2016 